Published in "Physical Review A 77(4): 040701, 2008"

which should be cited to refer to this work.

\title{
Absolute cross sections for dissociative electron attachment to acetylene and diacetylene
}

\author{
Olivier May, Juraj Fedor, Bogdan C. Ibănescu, and Michael Allan \\ Department of Chemistry, University of Fribourg, Fribourg, Switzerland
}

\begin{abstract}
Absolute cross sections for the production of the two astronomy-relevant negative ions $\mathrm{H}-\mathrm{C} \equiv \mathrm{C}^{-}$and $\mathrm{H}-\mathrm{C} \equiv \mathrm{C}-\mathrm{C} \equiv \mathrm{C}^{-}$by dissociative electron attachment to acetylene $\mathrm{C}_{2} \mathrm{H}_{2}$ and diacetylene $\mathrm{C}_{4} \mathrm{H}_{2}$ were measured (with a $\pm 25 \%$ error bar). Acetylene yielded the $\mathrm{C}_{2} \mathrm{H}^{-}$ion at an electron energy of $2.95 \mathrm{eV}$ with a cross section of $3.6 \pm 0.9 \mathrm{pm}^{2}$ and also the $\mathrm{C}_{2}^{-}$ion at $8.1 \mathrm{eV}$ with a cross section of $4.1 \pm 1 \mathrm{pm}^{2}$. Diacetylene yielded the $\mathrm{C}_{4} \mathrm{H}^{-}$ion at $2.5 \mathrm{eV}$ with a cross section of $3.0 \pm 0.8 \mathrm{pm}^{2}$ and at $5.25 \mathrm{eV}$ with a cross section of $73 \pm 17 \mathrm{pm}^{2}$. Weaker $\mathrm{C}_{4}^{-}, \mathrm{C}_{2} \mathrm{H}^{-}$, and $\mathrm{C}_{2}^{-}$signals were also observed from diacetylene. The identity of the negative ion resonances mediating the dissociation and the consequences for the production of these ions in discharges are discussed. An alternate path for $\mathrm{C}_{4} \mathrm{H}^{-}$formation, from the $\mathrm{O}^{-}-\mathrm{C}_{4} \mathrm{H}_{2}$ ion-molecule reaction, was also observed.
\end{abstract}

PACS number(s): $34.80 . \mathrm{Ht}, 52.20 . \mathrm{Fs}, 52.20 . \mathrm{Hv}$

The identifications of the negative ions $\mathrm{C}_{6} \mathrm{H}^{-}[1], \mathrm{C}_{4} \mathrm{H}^{-}$ [2] and $\mathrm{C}_{8} \mathrm{H}^{-}[3,4]$ in outer space are among the most exciting recent discoveries in astronomy. A necessary prerequisite for the assignment of the observed astronomical bands were laboratory microwave spectra $[1,5]$ —recorded with negative ions prepared in discharges containing acetylene $\mathrm{H}-\mathrm{C} \equiv \mathrm{C}-\mathrm{H}$ and diacetylene $\mathrm{H}-\mathrm{C} \equiv \mathrm{C}-\mathrm{C} \equiv \mathrm{C}-\mathrm{H}$. The knowledge of electron-induced chemistry of the $\mathrm{C}_{2 n} \mathrm{H}_{2}$ class of compounds is thus of great interest if we wish to address the question of how the $\mathrm{C}_{2 n} \mathrm{H}^{-}$ions are formed, primarily in laboratory discharges.

The most important primary electron-induced process leading to negative ion fragments is dissociative electron attachment (DEA), and the present work reports experimental absolute cross sections for this process in acetylene and diacetylene. These two compounds were found also in the upper layers of planetary atmospheres [6,7] and in flames [8]. Both environments contain free electrons and the present electron-induced processes could consequently also play a role there.

The desired quantitative cross sections were obtained by combining the results from two mutually complementary instruments.

(a) A dissociative electron attachment spectrometer described previously [9]. It employs a trochoidal electron monochromator to prepare a magnetically collimated beam of quasi-monoenergetic electrons, which is directed into a target chamber filled with a quasistatic sample gas. Fragment anions are extracted at $90^{\circ}$ and directed into a quadrupole mass spectrometer.

(b) A newly constructed total ion collection tube having the same basic principle of operation as that of Rapp and Briglia [10]. Fragment ions were collected at electrodes surrounding the electron beam in a collision chamber. A smoothly varying background of scattered electrons also reached the ion collecting electrodes after multiple collisions with the gas, and was subtracted. The cross section was calculated from the ion current, the incident electron beam intensity, and the sample gas pressure measured with a capacitance manometer. The electron current varied between $50 \mathrm{nA}$ and $2 \mu \mathrm{A}$, and the sample pressure between $0.05 \times 10^{-3}$ and $0.3 \times 10^{-3}$ mbars. Measurements were performed in two modes: (1) In a field-free target chamber and (2) with an ion extraction field of up to $6 \mathrm{~V} / \mathrm{cm}$. The former mode is similar to that employed by Aflatooni and Burrow [11]. The results, over the range of pressures and beam currents, agreed within about $\pm 20 \%$ and we report the average value, with an error bar of $\pm 25 \%$. The instrument was tested on the $\mathrm{O}^{-}$yield from $\mathrm{O}_{2}, \mathrm{CO}_{2}$, and $\mathrm{N}_{2} \mathrm{O}$, and a good agreement with the results of Rapp and Briglia [10] was obtained (Table I).

The dashed curve in Fig. 1 shows the absolute data, without mass resolution, obtained from the magnitude of the ion current in instrument (b). Earlier work [14-16] showed that the $2.95 \mathrm{eV}$ band is due to $\mathrm{C}_{2} \mathrm{H}^{-}$and the $8.1 \mathrm{eV}$ band to $\mathrm{C}_{2}^{-}$. The present value of the cross section at $2.95 \mathrm{eV}$ is higher than the value of Azria and Fiquet-Fayard [15] (Table I), with the difference being about equal to the combined error limits. Our value is also higher for the $8.1 \mathrm{eV}$ band although here the values are within the combined error limits. The present value at $2.95 \mathrm{eV}$ is in an excellent agreement with the calculated result of Chourou and Orel [12]. (The degree of agreement is presumably to some degree fortuitous in view of the $25 \%$ error bar of the experiment.) Figure 1 shows also the yield of the $\mathrm{C}_{2} \mathrm{H}^{-}$fragment measured by the mass resolved experiment, normalized to the absolute measurement at $2.95 \mathrm{eV}$. It reveals a second, weaker band peaking at $7.45 \mathrm{eVwhich}$ is obscured by background variations in the absolute measurement. The earlier work $[14,15]$ revealed also $\mathrm{H}^{-}$production.

TABLE I. DEA cross sections $\left(\mathrm{pm}^{2}\right)$.

\begin{tabular}{llccc}
\hline \hline Target & Energy & Product & This work & Lit. $^{{ }^{a}}$ \\
\hline $\mathrm{C}_{2} \mathrm{H}_{2}$ & 2.95 & $\mathrm{C}_{2} \mathrm{H}^{-}$ & 3.6 & $2.2 \pm 0.3$ \\
& 8.1 & $\mathrm{C}_{2}^{-}$ & 4.1 & $3.1 \pm 0.4$ \\
$\mathrm{C}_{4} \mathrm{H}_{2}$ & 2.50 & $\mathrm{C}_{4} \mathrm{H}^{-}$ & 3.0 & \\
& 5.25 & $\mathrm{C}_{4} \mathrm{H}^{-}$ & 73 & \\
$\mathrm{O}_{2}$ & 6.5 & $\mathrm{O}^{-}$ & 126 & 140 \\
$\mathrm{CO}_{2}$ & 8.1 & $\mathrm{O}^{-}$ & 37.4 & 42.4 \\
$\mathrm{~N}_{2} \mathrm{O}$ & 2.2 & $\mathrm{O}^{-}$ & 830 & 860 \\
\hline \hline
\end{tabular}

${ }^{a}$ References [10] $\left(\mathrm{O}_{2}, \mathrm{CO}_{2}\right.$ and $\left.\mathrm{N}_{2} \mathrm{O}\right)$ and [15] $\left(\mathrm{C}_{2} \mathrm{H}_{2}\right)$. 


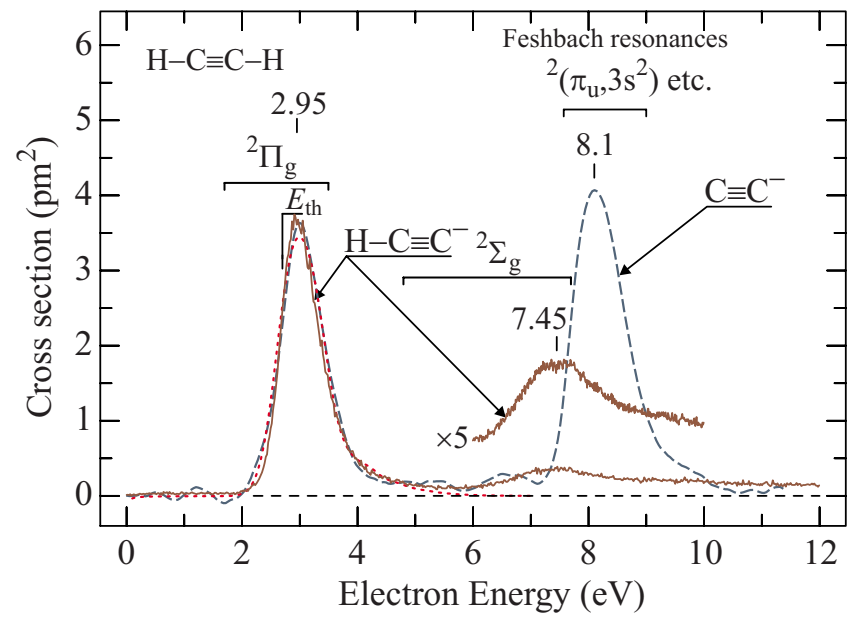

FIG. 1. (Color online) Dissociative electron attachment cross sections of acetylene. The dashed curve shows the absolute data, without mass resolution; the continuous curve is the yield of mass 25 fragment from the relative but mass resolved measurement, normalized to the absolute data. The dotted curve is the calculated cross section of Chourou and Orel [12]. The threshold energy $E_{\mathrm{th}}$, and the positions of the ${ }^{2} \Pi_{g},{ }^{2} \Sigma_{g}$, and the Feshbach resonances derived from earlier vibrational excitation [13] and electron transmission [14] work are indicated.

Dissociative electron attachment is nearly always a resonant process, it proceeds via a "resonance," a given state of a negative ion of the target molecule, which is generally very short-lived (of the order of a classical vibrational period) because of fast autodetachment. Independent information on acetylene resonances was obtained from vibrational excitation [13] and electron transmission [14]. These methods identified a ${ }^{2} \Pi_{g}$ shape resonance, due to a temporary occupation of the $\pi_{g}\left(\pi^{*}\right)$ LUMO of acetylene, extending from about 1.7 to $3.5 \mathrm{eV}$ and peaking at $2.6 \mathrm{eV}$, as indicated in Fig. 1.

Shape resonances with temporary occupation of $\sigma_{\mathrm{C}-\mathrm{H}}^{*}$ orbitals have been identified by vibrational excitation in many hydrocarbons, for example propane [17] or ethene [18]. They peak around $7.5 \mathrm{eV}$ and are several $\mathrm{eV}$ wide. A similar resonance may also be present in acetylene, but is unlikely to play a substantial role in dissociative electron attachment around $3 \mathrm{eV}$ because of its high energy and extremely large autodetachment width. We therefore prefer the assignment of the present $\mathrm{C}_{2} \mathrm{H}^{-}$band to the ${ }^{2} \Pi_{g}$ resonance.

The onset of the $\mathrm{C}_{2} \mathrm{H}^{-}$production coincides with the energetic threshold of the process (Table II). This indicates that the $\mathrm{C}_{2} \mathrm{H}^{-}$ion is produced with little excess energy, in its ${ }^{1} \Sigma$ electronic ground state, and that the dissociation proceeds without an activation barrier.

The dissociation of the ${ }^{2} \Pi_{g}$ resonance is symmetryforbidden in the linear geometry, but is made possible by vibronic coupling between the $\pi^{*}$ and the $\sigma^{*}$ resonances which makes it bent [12-14]. The situation, where vibronic coupling in negative ion resonances leads to symmetry lowering which opens a barrier-free path for a nominally forbidden dissociation, is quite common. It was encountered for example in chlorobenzene [19]. The large autodetachment
TABLE II. Threshold energies (eV).

\begin{tabular}{llll}
\hline \hline Target & Products & Calc. ${ }^{\text {a }}$ & Expt. \\
\hline $\mathrm{C}_{2} \mathrm{H}_{2}$ & $\mathrm{C}_{2} \mathrm{H}^{-}+\mathrm{H}$ & 2.70 & $2.744 \pm 0.007^{\mathrm{b}}$ \\
& $\mathrm{C}_{2}^{-}+\mathrm{H}_{2}$ & 2.81 & \\
& $\mathrm{C}_{2}^{-}+\mathrm{H}+\mathrm{H}$ & 7.4 & \\
$\mathrm{C}_{4} \mathrm{H}_{2}$ & $\mathrm{C}_{4} \mathrm{H}^{-}+\mathrm{H}$ & 2.07 & $1.94 \pm 0.08^{\mathrm{c}}$ \\
& $\mathrm{C}_{4}^{-}+\mathrm{H}_{2}$ & 3.50 & \\
& $\mathrm{C}_{4}^{-}+\mathrm{H}+\mathrm{H}$ & 8.1 & \\
& $\mathrm{C}_{2} \mathrm{H}^{-}+\mathrm{C}_{2} \mathrm{H}$ & 4.0 & \\
& $\mathrm{C}_{2}^{-}+\mathrm{C}_{2} \mathrm{H}_{2}$ & 2.93 & \\
& $\mathrm{C}_{2}^{-}+\mathrm{C}_{2} \mathrm{H}+\mathrm{H}$ & 8.7 &
\end{tabular}

${ }^{\mathrm{a}}$ Using the Beeke three-parameter Lee-Yang-Parr hybrid functional 6-311 and Gaussian $(2 d f, 2 p)$ model as in Ref. [9].

${ }^{\mathrm{b}}$ Calculated from the electron affinity of $\mathrm{C}_{2} \mathrm{H}$ and the $\mathrm{C}-\mathrm{H}$ bond dissociation energy ([20] and references therein).

${ }^{\mathrm{c}}$ Calculated from the experimental gas phase acidity [20].

width of the ${ }^{2} \Pi_{g}$ shape resonance, revealed by the absence of vibrational (boomerang) structure in the vibrational excitation cross section [13], and the necessity of the hydrogen atom to move out of the linear geometry in the course of the dissociation result in an unfavorable dissociationautodetachment competition and explain the small magnitude of the cross section and the large observed $\mathrm{H}$ or D isotope effect of $\geq 11$ [15].

Vibrational excitation revealed a broad ${ }^{2} \Sigma_{g}$ core excited resonance extending from about 4.8 to $7.7 \mathrm{eV}$ and peaking at $6.2 \mathrm{eV}$ [13], as indicated in Fig. 1, but the observed $7.45 \mathrm{eV}$ $\mathrm{C}_{2} \mathrm{H}^{-}$band is higher in energy and cannot be assigned to this resonance. The energy and width of the $7.45 \mathrm{eV} \mathrm{C}_{2} \mathrm{H}^{-}$band is reminiscent of the ${ }^{1} \Delta_{u}\left(\pi, \pi^{*}\right)$ band in the energy-loss spectrum of acetylene [14]. Dissociative electron attachment bands which have nearly the same energy as, and resemble in shape, low-lying singlet valence excited states of the target molecule have been found in a number of unsaturated compounds and assigned to resonances where an $s$-like electron is weakly bound to a valence-excited core $[21,22]$. The $7.45 \mathrm{eV}$ dissociative attachment band of acetylene is probably of this type-associated with the ${ }^{1} \Delta_{u}$ excited state of $\mathrm{C}_{2} \mathrm{H}_{2}$.

The $8.1 \mathrm{eV} \mathrm{C}_{2}^{-}$band has vibrational structure when recorded with higher resolution and has been assigned to several Feshbach resonances with a hole in the $\pi_{u}$ orbital and two electrons in Rydberg-like $3 s$ and/or $3 p$ orbitals $[14,16]$.

The dashed curve in Fig. 2 shows the absolute data, without mass resolution, for diacetylene. The figure shows also the yield of the $\mathrm{C}_{4} \mathrm{H}^{-}$fragment measured by the mass resolved experiment and normalized to the absolute measurement. It reveals a lower-lying band peaking at $2.5 \mathrm{eV}$ which is too weak to be visible in the absolute measurement.

Independent information on the diacetylene resonances was obtained from transmission and vibrational excitation spectra [23]. These methods identified a ${ }^{2} \Pi_{u}$ shape resonance due to a temporary occupation of the $\pi_{u}$ LUMO of diacetylene, peaking at $1.0 \mathrm{eV}$ and extending from about 0.6 to $2.2 \mathrm{eV}$, as indicated in Fig. 2. This resonance has a longer 


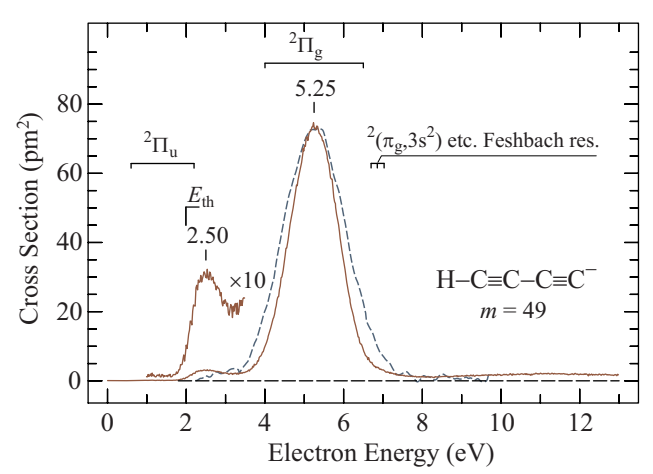

FIG. 2. (Color online) Yield of the mass 49 fragment from diacetylene. The dashed curve is the absolute data, the continuous curve is the relative, mass resolved measurement, normalized to the absolute measurement at $5.25 \mathrm{eV}$. The threshold energy $E_{\mathrm{th}}$, and the positions of the ${ }^{2} \Pi_{u},{ }^{2} \Pi_{g}$, and the Feshbach resonances are indicated.

lifetime (slower autodetachment) than ${ }^{2} \Pi_{g}$ resonance of acetylene, as indicated by boomerang (vibrational) structure [23]. A second, broader resonance has been found in the transmission spectrum, peaking at $5.6 \mathrm{eV}$ and assigned as a predominantly shape ${ }^{2} \Pi_{g}$ resonance. The singly occupied orbitals of these two resonances are approximately the in-phase and out-of-phase combinations of the acetylene LUMO.

The onset of the $\mathrm{C}_{4} \mathrm{H}^{-}$production (Fig. 2) coincides with the energetic threshold of the process $\left(E_{\mathrm{th}}=2.07 \mathrm{eV}\right.$, Table II), which is about $1 \mathrm{eV}$ above the peak of the ${ }^{2} \Pi_{u}$ resonance. The influence of this resonance extends well above its peak, however, because of its Franck-Condon and autodetachment widths, and the $2.5 \mathrm{eV} \mathrm{C}_{4} \mathrm{H}^{-}$band can be assigned as being mediated by the high-energy tail of the ${ }^{2} \Pi_{u}$ resonance. As in the case of acetylene, the $\mathrm{C}_{4} \mathrm{H}^{-}$ion is produced in its ${ }^{1} \Sigma$ electronic ground state and the dissociation is symmetry-forbidden in the linear geometry. It is made possible by vibronic coupling between the $\pi^{*}$ and the $\sigma^{*}$ resonances which makes the ${ }^{2} \Pi_{u}$ resonance bent. Evidence for the bent geometry was obtained already from the fact that it caused strong excitation of bending vibration [23].

The peak value of the cross section at $2.5 \mathrm{eV}$ is comparable to that of the $2.95 \mathrm{eV}$ band in acetylene. This is presumably the result of compensation of two effects: (i) The longer autodetachment lifetime of the ${ }^{2} \Pi_{u}$ resonance in diacetylene as compared to the ${ }^{2} \Pi_{g}$ resonance of acetylene tends to increase the cross section. (ii) The fact that the center of the ${ }^{2} \Pi_{u}$ resonance in diacetylene is situated well below the dissociative electron attachment threshold decreases the cross section.

The assignment of the $5.25 \mathrm{eV}$ band is less certain. In terms of energy the band coincides with the expected position of the ${ }^{2} \Pi_{g}$ shape resonance, with a temporary occupation of a MO consisting essentially of the out-of-phase combination of the two acetylene $\pi^{*}$ MOs. Because of its high energy this shape resonance is expected to have a large autodetachment width, however, and the large magnitude of the dissociative electron attachment cross section indicates a resonance with a slower autodetachment, such as a core excited resonance. In fact, the ${ }^{2} \Pi_{g}$ shape resonance is ener-

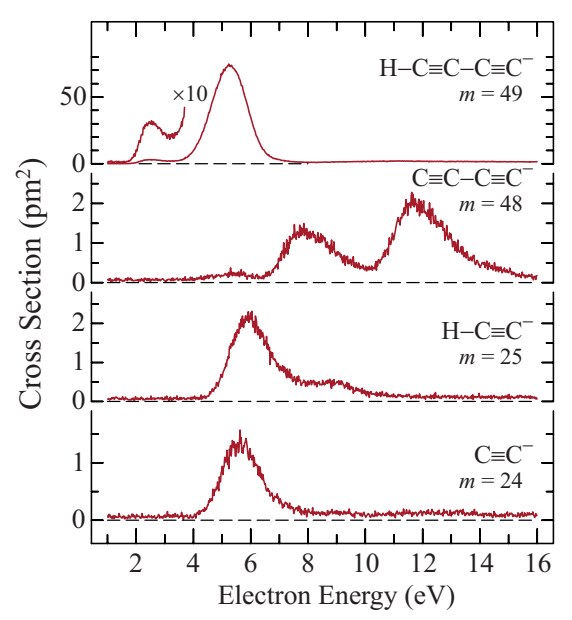

FIG. 3. (Color online) Yields of fragment of various masses from diacetylene. The data was normalized to the absolute measurement shown in Fig. 2 using the relative count rates.

getically close to low-lying electronically excited states which could serve as parent states for core excited resonances. In particular, it nearly coincides with the ${ }^{1} \Delta_{u}$ $(\mathrm{HOMO} \rightarrow$ LUMO) valence-excited state with a vertical transition energy of $5.5 \mathrm{eV}$ [24]. Two core-excited resonances, one consisting of an $s$-like electron around the ${ }^{1} \Delta_{u}$ excited state, the other having the configuration ${ }^{2}\left(\pi_{g}, \pi_{u}^{2}\right)^{2} \Pi_{g}$, are consequently expected near $5.5 \mathrm{eV}$. The latter of these two resonances has the right symmetry to mix with the ${ }^{2} \Pi_{g}$ shape resonance configuration, so that the nominally shape resonance probably involves mixing of a "single particle" and a core excited "two particles-one hole" configurations.

About $3.25 \mathrm{eV}$ excess energy are available at the $5.25 \mathrm{eV}$ band and part of the $\mathrm{C}_{4} \mathrm{H}^{-}$ions could thus be formed in an excited state, in particular the ${ }^{1} A^{\prime}$ dipole bound state studied by Pino et al. [25] and Pachkov et al. [26]. Their rotationally resolved spectra showed that the $\mathrm{C}_{4} \mathrm{H}^{-}$ion in this state is non-linear and consists of an electron loosely bound to the $\mathrm{C}_{4} \mathrm{H}^{\prime}$ radical in its $A{ }^{2} \Pi$ excited state which has a large dipole moment of 5D. The ground vibrational level lies about $70 \mathrm{~cm}^{-1}(9 \mathrm{meV}$ ) below the detachment threshold (which is equal to the electron affinity, $3.56 \mathrm{eV}[25,27,28]$ ).

Spectra of other fragments formed in electron collisions with diacetylene are shown in Fig. 3. The cross sections were too low for direct measurement of the absolute values with the instrument (b), but the relative count rates from instrument (a) were normalized to the absolute value of the $\mathrm{C}_{4} \mathrm{H}^{-}$ production at $5.25 \mathrm{eV}$. The energetic thresholds (Table II) indicate that the acetylene molecule (and not $\mathrm{C}_{2} \mathrm{H}+\mathrm{H}$ ) must be formed as the neutral fragment to accompany $\mathrm{C}_{2}^{-}$. This is surprising because a long shift of a hydrogen atom is required. Similarly, the formation of $\mathrm{C}_{4}^{-}$below $8.1 \mathrm{eV}$ requires that $\mathrm{H}_{2}$ is the neutral fragment and not two $\mathrm{H}$ atoms. A broad $\mathrm{H}^{-}$band peaking at about $8.5 \mathrm{eV}$, about $5 \times$ weaker than the highest $\mathrm{C}_{4}^{-}$band, was also observed but is not shown in Fig. 3.

In conclusion, dissociative electron attachment to acetylene and diacetylene yields the $\mathrm{C}_{2} \mathrm{H}^{-}$and $\mathrm{C}_{4} \mathrm{H}^{-}$ions at energies below about $3.5 \mathrm{eV}$, relevant in discharge conditions. 
The cross sections have similar magnitudes in both compounds, but this is a result of two opposing effects. In comparison with acetylene, the lowest shape resonance in diacetylene has a slower autodetachment rate, favoring dissociation, but it is at a lower energy, resulting in a less favorable overlap with the dissociative electron attachment threshold. The signals appear at their energetic thresholds, indicating absence of barrier along the dissociation path despite the fact that the dissociation of the ${ }^{2} \Pi$ resonances is $a$ priori forbidden in the linear geometry. The magnitudes of the cross sections at these low-energy bands are much smaller than, for example, that for the $\mathrm{O}^{-}$production from $\mathrm{N}_{2} \mathrm{O}$ (Table I). Ion-molecule reactions, such as proton abstraction by a strong base, may thus be an important alternate path for the formation of the $\mathrm{C}_{4} \mathrm{H}^{-}$ion in discharges. To test this possibility, we carried out the experiment in the instrument (a) with a mixture of diacetylene and $\mathrm{CO}_{2}$ in the target chamber. In this way we prepared $\mathrm{O}^{-}$ions in situ at 4.4 and $8.1 \mathrm{eV}$ electron energy (Ref. [10] and Table I), and observed a strong $\mathrm{C}_{4} \mathrm{H}^{-}$signal at these energies, which must result from $\mathrm{O}^{-}+\mathrm{C}_{4} \mathrm{H}_{2}$ collisions.

Diacetylene has a second band at $5.25 \mathrm{eV}$, with an about $20 \times$ larger cross section. The larger cross section at this band is probably a consequence of contribution of coreexcited resonances, which are energetically lower in diacetylene because of the lower-lying parent excited states of the target molecule, and which typically have slower autodetachment rates. This band is less relevant under discharge conditions where electron energy distribution peaks at $1-2 \mathrm{eV}$, however.

We thank to John P. Maier and to Jacques Lecoultre for a generous sample of diacetylene. We also thank John P. Maier and Sandra Brünken for inspiring discussions. This research is part of the Swiss National Science Foundation Project No. 200020-113599/1 and of COST Action CM0601.
[1] M. C. McCarthy, C. A. Gottlieb, H. Gupta, and P. Thaddeus, Astrophys. J. Lett. 652, L141 (2006).

[2] J. Cernicharo, M. Guelin, M. Agundez, K. Kawaguchi, M. McCarthy, and P. Thaddeus, Astrophys. J. Lett. 467, L37 (2007).

[3] S. Brünken, H. Gupta, C. A. Gottlieb, M. C. McCarthy, and P. Thaddeus, Astrophys. J. Lett. 664, L43 (2007).

[4] K. Kawaguchi, R. Fujimori, S. Aimi, S. Takano, E. Y. Okabayashi, H. Gupta, S. Brünken, C. A. Gootlieb, M. C. McCarthy, and P. Thaddeus, Publ. Astron. Soc. Jpn. 59, L47 (2007).

[5] H. Gupta, S. Brünken, F. Tamassia, C. A. Gottlieb, M. C. McCarthy, and P. Thaddeus, Astrophys. J. Lett. 655, L57 (2007).

[6] D. E. Shemansky, A. I. F. Stewart, R. A. West, L. W. Esposito, J. T. Hallett, and X. Liu, Science 308, 978 (2005).

[7] M. Burgdorf, G. Orton, J. van Cleve, V. Meadows, and J. Houck, Icarus 184, 634 (2006).

[8] H. Gueniche, P. Glaude, R. Fournet, and F. Battin-Leclerc, Combust. Flame 151, 245 (2007).

[9] B. C. Ibănescu, O. May, A. Monney, and M. Allan, Phys. Chem. Chem. Phys. 9, 3163 (2007).

[10] D. Rapp and D. D. Briglia, J. Chem. Phys. 43, 1480 (1965).

[11] A. Aflatooni and P. D. Burrow, J. Chem. Phys. 113, 1455 (2000).

[12] S. T. Chourou and A. E. Orel, Phys. Rev. A (to be published).

[13] L. Andrić and R. I. Hall, J. Phys. B 21, 355 (1988).

[14] R. Dressler and M. Allan, J. Chem. Phys. 87, 4510 (1987).
[15] R. Azria and F. Fiquet-Fayard, J. Phys. (Paris) 33, 663 (1972).

[16] R. Abouaf, L. Andrić, R. Azria, and M. Tronc, in Proceedings of the 12th International Conference on the Physics of Electronic and Atomic Collisions, edited by S. Datz (NorthHolland, Amsterdam, 1981), p. 409.

[17] M. Allan and L. Andrić, J. Chem. Phys. 105, 3559 (1996).

[18] I. C. Walker, A. Stamatovic, and S. F. Wong, J. Chem. Phys. 69, 5532 (1978).

[19] T. Skalický and M. Allan, J. Phys. B 37, 4849 (2004).

[20] Y. Shi and K. M. Ervin, Chem. Phys. Lett. 318, 149 (2000).

[21] R. A. Dressler, M. Allan, and M. Tronc, Chem. Phys. 20, 393 (1987).

[22] V. I. Khvostenko, A. S. Vorob'yov, and O. G. Khvostenko, J. Phys. B 23, 1975 (1990).

[23] M. Allan, Chem. Phys. 86, 303 (1984).

[24] M. Allan, J. Chem. Phys. 80, 6020 (1984).

[25] T. Pino, M. Tulej, F. Güthe, M. Pachkov, and J. P. Maier, J. Chem. Phys. 116, 6126 (2002).

[26] M. Pachkov, T. Pino, M. Tulej, F. Güthe, K. Tikhomirov, and J. P. Maier, Mol. Phys. 101, 538 (2003).

[27] T. R. Taylor, C. Xu, and D. M. Neumark, J. Chem. Phys. 108, 10018 (1998).

[28] J. Zhou, E. Garand, and D. M. Neumark, J. Chem. Phys. 127, 154320 (2007) 